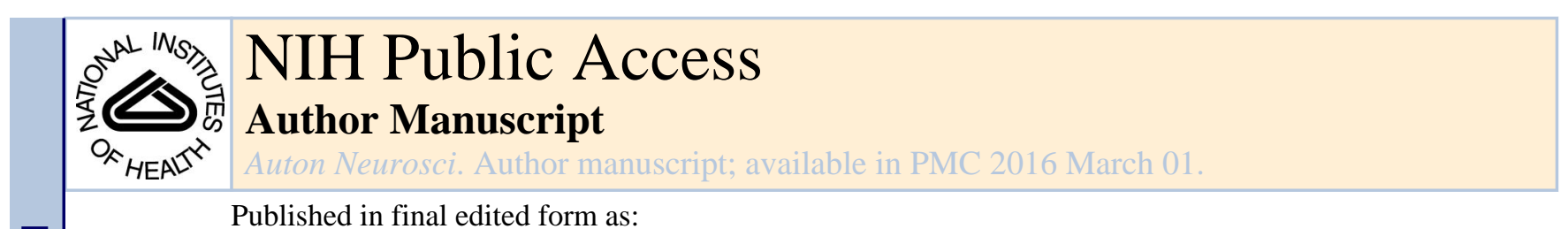

Published in final edited form as:

Auton Neurosci. 2015 March ; 188: 64-68. doi:10.1016/j.autneu.2014.10.019.

\title{
Functional sympatholysis in hypertension
}

\author{
Gail D. Thomas \\ Heart and Vascular Institute, Penn State College of Medicine, Hershey, PA, USA
}

\begin{abstract}
Sympathetic vasoconstriction is normally attenuated in exercising muscle by local changes in muscle metabolites and other substances that reduce vascular responsiveness to $a$-adrenergic receptor activation. Termed functional sympatholysis, this protective mechanism is thought to optimize muscle blood flow distribution to match perfusion with metabolic demand. Emerging evidence from both animal and human studies indicate that functional sympatholysis is impaired in hypertension and may constitute an important underlying cause of skeletal muscle malperfusion during exercise in this common cardiovascular condition. Findings from studies of animal models of hypertension and patients with essential hypertension will be integrated in this review to provide insight into the underlying mechanisms responsible for inappropriate sympathetic vasoconstriction in exercising muscle and the treatment options that may restore functional sympatholysis and improve muscle perfusion during exercise.
\end{abstract}

\section{Keywords}

sympathetic vasoconstriction; exercise; functional sympatholysis; hypertension

\section{Introduction}

Essential hypertension is one of the most prevalent chronic cardiovascular disorders, affecting $\approx 26 \%$ of the adult population worldwide (Kearney et al., 2005). A major cause of cardiovascular morbidity and mortality, hypertension is associated with an elevated systemic vascular resistance at rest and a blunted fall in vascular resistance during exercise (Conway, 1984; de Champlain et al., 1991; Lund-Johansen, 1991; Goodman et al., 1992).

Inappropriate activation of the sympathetic nervous system appears to play a major role in this circulatory dysfunction as regional sympathetic outflow to the heart, kidneys, and skeletal muscle is increased in $\approx 50 \%$ of hypertensive individuals (Parati and Esler, 2012; Mancia and Grassi, 2014). During exercise, sympathetic drive to skeletal muscle is further augmented in hypertensive individuals independent of the basal level of sympathetic activity (Rondon et al., 2006; Smith et al., 2006; Delaney et al., 2010; Vongpatanasin et al., 2011;

(C) 2014 Elsevier B.V. All rights reserved.

Correspondence: Gail D. Thomas Heart and Vascular Institute Penn State College of Medicine 500 University Drive, H047 Hershey, PA 17033 gthomas4@hmc.psu.edu.

Publisher's Disclaimer: This is a PDF file of an unedited manuscript that has been accepted for publication. As a service to our customers we are providing this early version of the manuscript. The manuscript will undergo copyediting, typesetting, and review of the resulting proof before it is published in its final citable form. Please note that during the production process errors may be discovered which could affect the content, and all legal disclaimers that apply to the journal pertain. 
Price et al., 2013). Major targets of this exercise-induced sympathoexcitation are the small arteries and resistance arterioles of the skeletal muscle microcirculation, which normally demonstrate an attenuated constrictor response to sympathetic activation during exercise (Boegehold and Johnson, 1988; Anderson and Faber, 1991; VanTeeffelen and Segal, 2003). This functional sympatholysis is impaired in hypertensive animals and humans, resulting in reduced perfusion of the active muscles due to unrestrained sympathetic vasoconstriction (Zhao et al., 2006; Vongpatanasin et al., 2011; Fadel et al., 2012; Price et al., 2013). Findings from studies of animal models of hypertension and patients with essential hypertension will be integrated in this review to provide insight into the mechanisms that impair functional sympatholysis and the treatment options that may improve sympatholysis in this common cardiovascular disorder.

\section{Functional Sympatholysis: A Mechanism to Optimize Muscle Blood Flow During Exercise}

The term functional sympatholysis was coined in 1962 by Remensnyder et al. to describe the reduced vasoconstrictor response to sympathetic activation or intravascular norepinephrine that was observed in the contracting hindlimb muscles of anesthetized dogs. This seminal study confirmed and extended the findings of earlier dog studies by Rein in the 1930s (Rein, 1930; Rein, 1937) and showed that the vasoconstrictor responsiveness of the muscle vasculature declined markedly with only a small increase in muscle $\mathrm{O}_{2}$ uptake (Remensnyder et al., 1962). Subsequent studies in humans have shown that sympathetic vasoconstriction is attenuated at relatively low intensities of exercise and that this functional sympatholysis precedes the exercise-induced reflex increase in muscle sympathetic nerve activity, thereby protecting perfusion of the active muscles (Hansen et al., 1996; Tschakovsky et al., 2002; Wray et al., 2004). Functional sympatholysis has been demonstrated in numerous species (mouse, rat, hamster, cat, dog, and human) under diverse experimental conditions, suggesting that it is an important component of the integrated cardiovascular response to exercise.

More recent attention has been directed toward an improved understanding of the mechanistic underpinnings of functional sympatholysis. There is good agreement that functional sympatholysis is not an all-or-none phenomenon, but rather a continuum of vascular responsiveness that varies inversely with the strength of the vasoconstrictor stimulus and directly with the intensity of the muscular work (Thomas and Segal, 2004). Within the skeletal muscle microcirculation, functional sympatholysis is more pronounced in the small distal arterioles than in the large proximal arterioles and feed arteries (Folkow et al., 1971; Boegehold and Johnson, 1988; Anderson and Faber, 1991; VanTeeffelen and Segal, 2003). This allows the most metabolically active muscle fibers to be optimally perfused by the dilated distal vessels while retaining the ability to constrict the proximal vessels and regulate systemic arterial pressure. These heterogenous responses were originally attributed to a differential distribution of $a_{1^{-}}$and $a_{2}$-adrenergic receptor subtypes on the proximal and distal arterioles, respectively, coupled with a greater sensitivity of $\mathrm{a}_{2}$ adrenergic vasoconstriction to metabolic inhibition (Faber, 1988; Anderson and Faber, 1991). However, more recent evidence has questioned whether a-adrenergic receptor 
subtype distribution in the microcirculation is uniform among all muscles (Moore et al., 2010), suggesting that other factors underlie the more pronounced functional sympatholysis in the distal arterioles (Roy and Secomb, 2014).

There is substantial evidence to indicate that functional sympatholysis is mediated by local changes within the active muscles, but the specific mechanisms remain incompletely understood. Sympathetic responses may be modulated by accumulation of muscle metabolites in the interstitium (Figure 1), release of vasodilators from the endothelium due to increased wall shear stress, and/or release of vasodilators from blood constituents (Clifford and Hellsten, 2004; Thomas and Segal, 2004; Saltin and Mortensen, 2012). Sympathetic vasoconstriction also can be attenuated by upstream conduction of local vasodilator signals that are propagated along the vessel wall, providing a means of coordinating arteriolar dilation within the muscle microcirculation (Segal, 2005). Putative mediators of functional sympatholysis that are supported by experimental evidence include potassium ions, hydrogen ions, prostaglandins, nitric oxide (NO), ATP, tissue hypoxia, and ATP sensitive potassium channels, although there currently is no strong consensus with regard to the relative importance of individual mechanisms (Clifford and Hellsten, 2004; Thomas and Segal, 2004; Saltin and Mortensen, 2012). It might be supposed that any vasodilating substance is a sympatholytic candidate, however, there does appear to be specificity in the signaling pathways that can modulate sympathetic vasoconstriction. Intraarterial infusion of adenosine, hydralazine, or isoproterenol cause large increases in total muscle blood flow, but none of these dilators reduce sympathetically-mediated vasoconstriction (Thomas et al., 1994; Thomas and Victor, 1998; Tschakovsky et al., 2002).

There is increasing recognition that functional sympatholysis likely plays an important role in the local regulation of arteriolar tone to appropriately distribute intramuscular blood flow to match perfusion and metabolic demand. An increase in sympathetic vasoconstriction threatens this balance by reducing and/or maldistributing muscle blood flow and $\mathrm{O}_{2}$ delivery with potential consequences ranging from impaired muscle performance and exercise intolerance to an exaggerated pressor response to exercise. The remainder of this review will focus on recent work suggesting that the conventional cardiovascular risk factor hypertension is a common underlying cause of impaired functional sympatholysis.

\section{Impaired Functional Sympatholysis in Hypertension}

Hypertension is characterized by microvascular dysfunction that contributes to elevated peripheral vascular resistance as well as decreased tissue and organ perfusion (Levy et al., 2008; Parati and Esler, 2012). Both functional (changes in vascular reactivity) and structural (vascular remodeling; rarefaction) abnormalities have been observed in the microcirculation of hypertensive animals and humans and there is evidence that functional changes can progress to structural changes (Levy et al., 2008). Heightened sympathetic vasoconstrictor responsiveness may contribute to hypertension-related microvascular abnormalities in the skeletal muscle microcirculation and would be expected to have more severe consequences when muscle metabolic demand is high, such as during exercise. Initial reports of impaired functional sympatholysis in rodent models of hypertension and in humans with essential hypertension offer some insights into the underlying mechanisms by which sympathetic 
regulation of muscle blood flow is altered in this disease (Zhao et al., 2006; Vongpatanasin et al., 2011; Price et al., 2013).

\section{3.a. Mechanistic Insight from Animal Studies}

Rats made hypertensive by infusion of angiotensin II (Ang II) for two weeks have impaired functional sympatholysis as evidenced by greater sympathetic vasoconstrictor responses in the contracting hindlimb muscles compared to vehicle controls (Zhao et al., 2006). The impaired sympatholysis does not reflect a general increase in sympathetic responsiveness because vasoconstrictor responses at rest are similar in Ang II hypertensive and normotensive rats (Zhao et al., 2006). This suggests that the local environment within the active muscles that normally promotes sympatholysis is altered in hypertension. The mechanism appears to involve oxidative stress because: (1) functional sympatholysis is restored by acute treatment with the superoxide dismutase mimetic tempol, (2) the gp91phox subunit (NOX2) of the superoxide-generating NADPH oxidase, which is known to be regulated by Ang II, is increased in skeletal muscle, and (3) superoxide production is abnormally increased in resting muscle and is further augmented during muscle contraction (Zhao et al., 2006) (Figure 1). An important mechanistic action of superoxide to impair functional sympatholysis by scavenging $\mathrm{NO}$ is suggested by the inability of tempol to restore sympatholysis in Ang II hypertensive rats pretreated with an inhibitor of nitric oxide synthase (Zhao et al., 2006).

A similar phenotype of impaired functional sympatholysis is observed in rats made hypertensive by unilateral renal artery stenosis (Goldblatt 2K1C model of renovascular hypertension), which increases endogenous Ang II production (Zhao et al., 2006). Dogs with renovascular hypertension also show exaggerated peripheral vasoconstriction in response to reflex sympathetic activation during mild treadmill exercise, although it is not clear how much of the constriction occurs in active muscle (Sala-Mercado et al., 2013). In contrast, functional sympatholysis is normal and oxidative stress is absent in rats made hypertensive by chronic infusion of norepinephrine, which does not activate NADPH oxidase (Zhao et al., 2006). Furthermore, infusion of Ang II to raise blood pressure acutely (within minutes) does not impair sympatholysis in rats (Thomas and Victor, 1998), reflecting the longer time course required for Ang II-induced increases in NADPH oxidase activity and expression to generate pathophysiologic levels of superoxide (Griendling et al., 1994).

One of the important conclusions that can be drawn from these findings is that an increase in blood pressure per se is not sufficient to attenuate functional sympatholysis. The effect of Ang II to cause oxidative stress, not raise blood pressure, appears to be a key pathophysiologic element. This is reinforced by recent work showing that sympatholysis is impaired when oxidative stress is induced in healthy rats and humans by nitroglycerin treatment, which does not increase arterial pressure (Fadel et al., 2012). Likewise, sympatholysis is impaired in normotensive rats with ischemic heart failure and is restored by tempol treatment, indicating a major mechanistic role of oxidative stress (Thomas et al., 2001). Interestingly, in mice treated with a subpressor dose of Ang II for one week, NADPH oxidase activity and superoxide production in skeletal muscle are increased and exercise tolerance is decreased, suggesting that muscle oxidative stress may play an important role to 
limit functional capacity in conditions associated with even modest increases in Ang II (Inoue et al., 2012).

A question that remains unresolved is the cellular source of the oxidative stress induced by Ang II that limits functional sympatholysis. NADPH oxidase is expressed in vascular smooth muscle, endothelial cells, and skeletal muscle fibers, all of which have been shown to increase superoxide production in response to Ang II (Griendling et al., 1994; Rajagopalan et al., 1996; Wei et al., 2006; Zhao et al., 2006; Inoue et al., 2012). However, increasing evidence indicates that activation of NADPH oxidase in the contracting muscle fibers is a major source of the superoxide produced in active muscle (Sakellariou et al., 2013).

\section{3.b. Mechanistic Insight from Human Studies}

The main finding of impaired functional sympatholysis in the contracting hindlimb muscles of young hypertensive rats has recently been translated to the exercising forearm muscles of middle-aged humans with untreated mild essential hypertension (140-159/90-99 mm Hg) (Vongpatanasin et al., 2011; Price et al., 2013). Subjects with uncomplicated Stage I hypertension were studied so that all vasoactive medications could be withdrawn for at least 4 weeks in order to minimize confounding influences on the sympathetic responses to exercise. The findings of these studies show that both the sympathoexcitatory response to handgrip exercise and the sympathetic vasoconstrictor responses in the contracting forearm are exaggerated in the hypertensive individuals (Vongpatanasin et al., 2011; Price et al., 2013). Excessive sympathetic activation coupled with impaired functional sympatholysis could have deleterious consequences for cardiovascular regulation during exercise, promoting a vicious cycle of muscle malperfusion followed by further sympathetic activation. Whether abnormal sympathetic control of the circulation during exercise worsens with the severity of hypertension is not known, but could add to the risk for adverse cardiovascular events in this patient population.

Antihypertensive treatment readily improves functional sympatholysis in subjects with mild hypertension, but different pharmacologic classes of antihypertensive drugs with similar effects on blood pressure differ in terms of their effect on sympatholysis (Vongpatanasin et al., 2011; Price et al., 2013). This provides some clues about the mechanisms responsible for impairing functional sympatholysis in essential hypertension. Sympatholysis is restored by treatment with the Ang II type 1 receptor blocker irbesartan or the third-generation vasodilating $\beta_{1}$-adrenergic receptor blocker nebivolol, but not by treatment with the thiazide diuretic chlorthalidone or the conventional $\beta_{1}$-adrenergic receptor blocker metoprolol (Vongpatanasin et al., 2011; Price et al., 2013). These findings suggest a major role of the renin-angiotensin system to enhance sympathetic vasoconstriction in the active muscles, which is consistent with the findings of the earlier hypertensive rat studies (Zhao et al., 2006). The differential effects of the $\beta$-blockers on sympatholysis is likely due to ancillary effects of nebivolol to improve NO signaling and/or reduce NADPH oxidase-dependent oxidative stress, although the precise mechanism of action in these human studies remains to be determined (Broeders et al., 2000; Oelze et al., 2006; Whaley-Connell et al., 2009). These findings also support the conclusion that an increase in blood pressure by itself does not 
impair functional sympatholysis as no improvement is seen by simply lowering blood pressure. Based on this work, it might be predicted that antihypertensive drugs that inhibit the renin-angiotensin system, mitigate oxidative stress, or increase NO bioavailability are more likely to have a dual effect to reduce blood pressure and improve sympathetic control of muscle blood flow during exercise.

Although irbesartan and nebivolol restore functional sympatholysis in hypertensive individuals, treatment with these drugs does not ameliorate the exaggerated sympathoexcitatory response to handgrip exercise (Vongpatanasin et al., 2011; Price et al., 2013). This finding suggests that different signaling pathways may be involved in the abnormal activation of sympathetic nerves and in the modulation of sympathetic vasoconstriction during exercise in hypertension. While this preliminary conclusion is based on results from a small number of hypertensive subjects, it implies that drug monotherapy may not be able to correct both of the abnormal sympathetic phenotypes. Exercise training is an effective non-pharmacological approach to reduce blood pressure in essential hypertension and has recently been shown to improve functional sympatholysis in the legs of middle-aged subjects with mild to moderate hypertension and in age-matched control subjects (Mortensen et al., 2014). The mechanism responsible for the training-induced improvement in sympatholysis is not clear, but may involve changes in the local generation of constrictor and dilator substances in the active muscles (Hansen et al., 2011; Hellsten et al., 2012; Jendzjowsky and Delorey, 2013). Further work is needed to understand these training-induced adaptations and to clarify the role that factors such as age and physical fitness play in the expression of functional sympatholysis in both hypertensive and normotensive individuals (Koch et al., 2003; Fadel et al., 2004; Dinenno et al., 2005; Mortensen et al., 2012a; Mortensen et al., 2012b).

\section{Summary}

Previous findings of impaired functional sympatholysis in hypertensive animals have now been translated to humans with essential hypertension. Although the consequences of impaired sympatholysis in hypertension are not fully understood, it may constitute an important underlying cause of skeletal muscle malperfusion during exercise (Saltin and Mortensen, 2012). Sympathetic vasoconstriction is enhanced in the contracting muscles of hypertensive animals by an Ang II-dependent mechanism that appears to promote oxidative stress and reduce NO signaling (Zhao et al., 2006). Therapeutic approaches to mitigate these effects, such as Ang II receptor blockers and exercise training, restore functional sympatholysis in hypertensive individuals and are likely to improve sympathetic regulation of muscle blood flow during exercise (Vongpatanasin et al., 2011; Price et al., 2013; Mortensen et al., 2014). Additional work is needed to determine if correcting the sympatholysis phenotype can improve functional capacity and reduce cardiovascular risk in hypertensive individuals.

\section{References}

Anderson KM, Faber JE. Differential sensitivity of arteriolar alpha 1- and alpha 2-adrenoceptor constriction to metabolic inhibition during rat skeletal muscle contraction. Circ. Res. 1991; 69:174184. [PubMed: 1647277] 
Boegehold MA, Johnson PC. Response of arteriolar network of skeletal muscle to sympathetic nerve stimulation. Am. J. Physiol. 1988; 254:H919-928. [PubMed: 3364596]

Broeders MA, Doevendans PA, Bekkers BC, Bronsaer R, van Gorsel E, Heemskerk JW, et al. Nebivolol: a third-generation beta-blocker that augments vascular nitric oxide release: endothelial beta(2)-adrenergic receptor-mediated nitric oxide production. Circulation. 2000; 102:677-684. [PubMed: 10931809]

Clifford PS, Hellsten Y. Vasodilatory mechanisms in contracting skeletal muscle. J. Appl. Physiol. 2004; 97:393-403. [PubMed: 15220322]

Conway J. Hemodynamic aspects of essential hypertension in humans. Physiol. Rev. 1984; 64:617660. [PubMed: 6369352]

de Champlain J, Petrovich M, Gonzalez M, Lebeau R, Nadeau R. Abnormal cardiovascular reactivity in borderline and mild essential hypertension. Hypertension. 1991; 17:III22-28. [PubMed: 2013489]

Delaney EP, Greaney JL, Edwards DG, Rose WC, Fadel PJ, Farquhar WB. Exaggerated sympathetic and pressor responses to handgrip exercise in older hypertensive humans: role of the muscle metaboreflex. Am. J. Physiol. Heart Circ. Physiol. 2010; 299:H1318-1327. [PubMed: 20802135]

Dinenno FA, Masuki S, Joyner MJ. Impaired modulation of sympathetic alpha-adrenergic vasoconstriction in contracting forearm muscle of ageing men. J. Physiol. 2005; 567:311-321. [PubMed: 15946964]

Faber JE. In situ analysis of alpha-adrenoceptors on arteriolar and venular smooth muscle in rat skeletal muscle microcirculation. Circ. Res. 1988; 62:37-50. [PubMed: 2891454]

Fadel PJ, Farias M Iii, Gallagher KM, Wang Z, Thomas GD. Oxidative stress and enhanced sympathetic vasoconstriction in contracting muscles of nitrate-tolerant rats and humans. J. Physiol. 2012; 590:395-407. [PubMed: 22106180]

Fadel PJ, Wang Z, Watanabe H, Arbique D, Vongpatanasin W, Thomas GD. Augmented sympathetic vasoconstriction in exercising forearms of postmenopausal women is reversed by oestrogen therapy. J. Physiol. 2004; 561:893-901. [PubMed: 15498809]

Folkow B, Sonnenschein RR, Wright DL. Loci of neurogenic and metabolic effects on precapillary vessels of skeletal muscle. Acta Physiol. Scand. 1971; 81:459-471. [PubMed: 5091106]

Goodman JM, McLaughlin PR, Plyley MJ, Holloway RM, Fell D, Logan AG, et al. Impaired cardiopulmonary response to exercise in moderate hypertension. Can. J. Cardiol. 1992; 8:363-371. [PubMed: 1535538]

Griendling KK, Minieri CA, Ollerenshaw JD, Alexander RW. Angiotensin II stimulates NADH and NADPH oxidase activity in cultured vascular smooth muscle cells. Circ. Res. 1994; 74:11411148. [PubMed: 8187280]

Hansen AH, Nyberg M, Bangsbo J, Saltin B, Hellsten Y. Exercise training alters the balance between vasoactive compounds in skeletal muscle of individuals with essential hypertension. Hypertension. 2011; 58:943-949. [PubMed: 21896936]

Hansen J, Thomas GD, Harris SA, Parsons WJ, Victor RG. Differential sympathetic neural control of oxygenation in resting and exercising human skeletal muscle. J. Clin. Invest. 1996; 98:584-596. [PubMed: 8755671]

Hellsten Y, Jensen L, Thaning P, Nyberg M, Mortensen S. Impaired formation of vasodilators in peripheral tissue in essential hypertension is normalized by exercise training: role of adenosine and prostacyclin. J. Hypertens. 2012; 30:2007-2014. [PubMed: 22902871]

Inoue N, Kinugawa S, Suga T, Yokota T, Hirabayashi K, Kuroda S, et al. Angiotensin II-induced reduction in exercise capacity is associated with increased oxidative stress in skeletal muscle. Am. J. Physiol. Heart Circ. Physiol. 2012; 302:H1202-1210. [PubMed: 22210751]

Jendzjowsky NG, Delorey DS. Short-term exercise training enhances functional sympatholysis through a nitric oxide-dependent mechanism. J. Physiol. 2013; 591:1535-1549. [PubMed: 23297301]

Kearney PM, Whelton M, Reynolds K, Muntner P, Whelton PK, He J. Global burden of hypertension: analysis of worldwide data. Lancet. 2005; 365:217-223. [PubMed: 15652604] 
Koch DW, Leuenberger UA, Proctor DN. Augmented leg vasoconstriction in dynamically exercising older men during acute sympathetic stimulation. J. Physiol. 2003; 551:337-344. [PubMed: 12824451]

Levy BI, Schiffrin EL, Mourad JJ, Agostini D, Vicaut E, Safar ME, et al. Impaired tissue perfusion: a pathology common to hypertension, obesity, and diabetes mellitus. Circulation. 2008; 118:968976. [PubMed: 18725503]

Lund-Johansen P. Twenty-year follow-up of hemodynamics in essential hypertension during rest and exercise. Hypertension. 1991; 18:III54-61. [PubMed: 1937687]

Mancia G, Grassi G. The Autonomic Nervous System and Hypertension. Circ. Res. 2014; 114:18041814. [PubMed: 24855203]

Moore AW, Jackson WF, Segal SS. Regional heterogeneity of alpha-adrenoreceptor subtypes in arteriolar networks of mouse skeletal muscle. J. Physiol. 2010; 588:4261-4274. [PubMed: 20807785]

Mortensen SP, Morkeberg J, Thaning P, Hellsten Y, Saltin B. Two weeks of muscle immobilization impairs functional sympatholysis but increases exercise hyperemia and the vasodilatory responsiveness to infused ATP. Am. J. Physiol. Heart Circ. Physiol. 2012a; 302:H2074-2082. [PubMed: 22408019]

Mortensen SP, Nyberg M, Gliemann L, Thaning P, Saltin B, Hellsten Y. Exercise training modulates functional sympatholysis and alpha-adrenergic vasoconstrictor responsiveness in hypertensive and normotensive individuals. J. Physiol. 2014; 592:3063-3073. [PubMed: 24860173]

Mortensen SP, Nyberg M, Winding K, Saltin B. Lifelong physical activity preserves functional sympatholysis and purinergic signalling in the ageing human leg. J. Physiol. 2012b; 590:62276236. [PubMed: 22966164]

Oelze M, Daiber A, Brandes RP, Hortmann M, Wenzel P, Hink U, et al. Nebivolol inhibits superoxide formation by NADPH oxidase and endothelial dysfunction in angiotensin II-treated rats. Hypertension. 2006; 48:677-684. [PubMed: 16940222]

Parati G, Esler M. The human sympathetic nervous system: its relevance in hypertension and heart failure. Eur. Heart J. 2012; 33:1058-1066. [PubMed: 22507981]

Price A, Raheja P, Wang Z, Arbique D, Adams-Huet B, Mitchell JH, et al. Differential effects of nebivolol versus metoprolol on functional sympatholysis in hypertensive humans. Hypertension. 2013; 61:1263-1269. [PubMed: 23547240]

Rajagopalan S, Kurz S, Munzel T, Tarpey M, Freeman BA, Griendling KK, et al. Angiotensin IImediated hypertension in the rat increases vascular superoxide production via membrane NADH/ NADPH oxidase activation. Contribution to alterations of vasomotor tone. J. Clin. Invest. 1996; 97:1916-1923. [PubMed: 8621776]

Rein H. Die interferenz der vasomotorischen regulationen. Klin. Wochenschr. 1930; 9:1485-1489.

Rein H. Die lokale stoffwechseleinschrankung bei reflektoriseh-nervoser durehblutungdrosselung. Arch. Ges. Physiol. 1937; 239:464.

Remensnyder JP, Mitchell JH, Sarnoff SJ. Functional sympatholysis during muscular activity. Observations on influence of carotid sinus on oxygen uptake. Circ. Res. 1962; 11:370-380. [PubMed: 13981593]

Rondon MU, Laterza MC, de Matos LD, Trombetta IC, Braga AM, Roveda F, et al. Abnormal muscle metaboreflex control of sympathetic activity in never-treated hypertensive subjects. Am. J. Hypertens. 2006; 19:951-957. [PubMed: 16942939]

Roy TK, Secomb TW. Functional sympatholysis and sympathetic escape in a theoretical model for blood flow regulation. Front. Physiol. 2014; 5:192. doi: 10.3389/fphys.2014.00192. [PubMed: 24904428]

Sakellariou GK, Vasilaki A, Palomero J, Kayani A, Zibrik L, McArdle A, et al. Studies of mitochondrial and nonmitochondrial sources implicate nicotinamide adenine dinucleotide phosphate oxidase(s) in the increased skeletal muscle superoxide generation that occurs during contractile activity. Antioxid. Redox Signal. 2013; 18:603-621. [PubMed: 23050834]

Sala-Mercado JA, Spranger MD, Abu-Hamdah R, Kaur J, Coutsos M, Stayer D, et al. Attenuated muscle metaboreflex-induced increases in cardiac function in hypertension. Am. J. Physiol. Heart Circ. Physiol. 2013; 305:H1548-1554. [PubMed: 24014673] 
Saltin B, Mortensen SP. Inefficient functional sympatholysis is an overlooked cause of malperfusion in contracting skeletal muscle. J. Physiol. 2012; 590:6269-6275. [PubMed: 22988143]

Segal SS. Regulation of blood flow in the microcirculation. Microcirculation. 2005; 12:33-45. [PubMed: 15804972]

Smith SA, Williams MA, Leal AK, Mitchell JH, Garry MG. Exercise pressor reflex function is altered in spontaneously hypertensive rats. J. Physiol. 2006; 577:1009-1020. [PubMed: 17023501]

Thomas GD, Hansen J, Victor RG. Inhibition of alpha 2-adrenergic vasoconstriction during contraction of glycolytic, not oxidative, rat hindlimb muscle. Am. J. Physiol. 1994; 266:H920 929. [PubMed: 7909201]

Thomas GD, Segal SS. Neural control of muscle blood flow during exercise. J. Appl. Physiol. 2004; 97:731-738. [PubMed: 15247201]

Thomas GD, Victor RG. Nitric oxide mediates contraction-induced attenuation of sympathetic vasoconstriction in rat skeletal muscle. J. Physiol. 1998; 506:817-826. [PubMed: 9503340]

Thomas GD, Zhang W, Victor RG. Impaired modulation of sympathetic vasoconstriction in contracting skeletal muscle of rats with chronic myocardial infarctions: role of oxidative stress. Circ. Res. 2001; 88:816-823. [PubMed: 11325874]

Tschakovsky ME, Sujirattanawimol K, Ruble SB, Valic Z, Joyner MJ. Is sympathetic neural vasoconstriction blunted in the vascular bed of exercising human muscle? J. Physiol. 2002; 541:623-635. [PubMed: 12042366]

VanTeeffelen JW, Segal SS. Interaction between sympathetic nerve activation and muscle fibre contraction in resistance vessels of hamster retractor muscle. J. Physiol. 2003; 550:563-574. [PubMed: 12754308]

Vongpatanasin W, Wang Z, Arbique D, Arbique G, Adams-Huet B, Mitchell JH, et al. Functional sympatholysis is impaired in hypertensive humans. J. Physiol. 2011; 589:1209-1220. [PubMed: 21224235]

Wei Y, Sowers JR, Nistala R, Gong H, Uptergrove GM, Clark SE, et al. Angiotensin II-induced NADPH oxidase activation impairs insulin signaling in skeletal muscle cells. J. Biol. Chem. 2006; 281:35137-35146. [PubMed: 16982630]

Whaley-Connell A, Habibi J, Johnson M, Tilmon R, Rehmer N, Rehmer J, et al. Nebivolol reduces proteinuria and renal NADPH oxidase-generated reactive oxygen species in the transgenic Ren2 rat. Am. J. Nephrol. 2009; 30:354-360. [PubMed: 19609077]

Wray DW, Fadel PJ, Smith ML, Raven P, Sander M. Inhibition of alpha-adrenergic vasoconstriction in exercising human thigh muscles. J. Physiol. 2004; 555:545-563. [PubMed: 14694145]

Zhao W, Swanson SA, Ye J, Li X, Shelton JM, Zhang W, et al. Reactive oxygen species impair sympathetic vasoregulation in skeletal muscle in angiotensin II-dependent hypertension. Hypertension. 2006; 48:637-643. [PubMed: 16940212] 


\section{Highlights}

- Sympathetic vasoconstriction normally is reduced in active skeletal muscle.

- Termed functional sympatholysis, this local modulation optimizes muscle blood flow.

- Hypertensive animals and humans demonstrate impaired functional sympatholysis.

- The mechanism involves angiotensin II, oxidative stress, and reduced nitric oxide.

- Sympatholysis is restored by select antihypertensive drugs or exercise training. 
Normotension

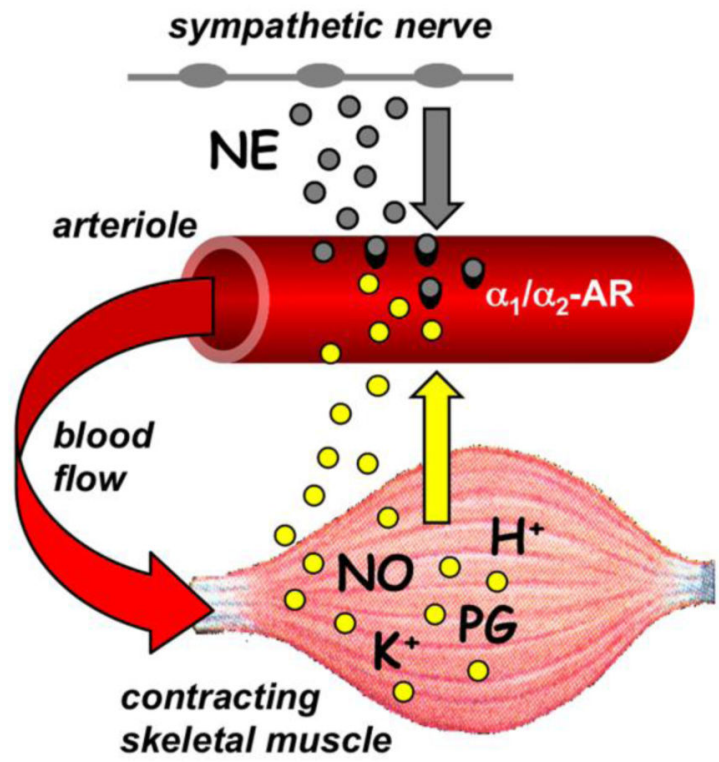

Hypertension

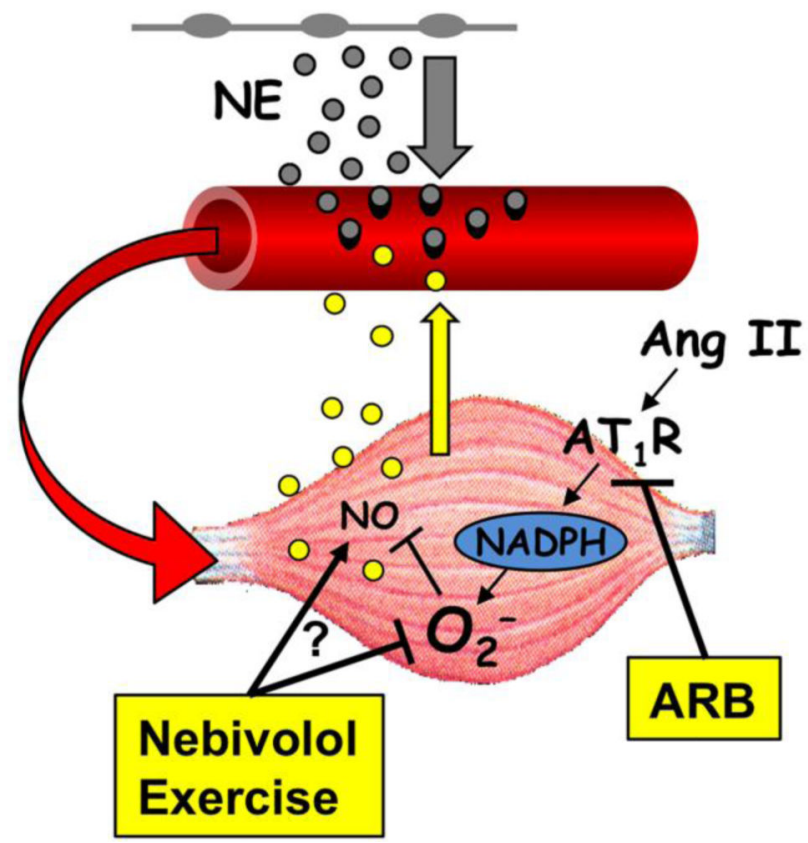

Figure 1.

Left panel, Shows some of the products of skeletal muscle contraction that can diffuse into the interstitium and cause functional sympatholysis by attenuating arteriolar constriction mediated by $a_{1}$ - and $\beta_{2}$-adrenergic receptors. Right panel, In hypertension, the sympatholytic effect of muscle contraction is impaired by an Ang II-dependent upregulation of NADPH oxidase, increased $\mathrm{O}_{2}^{-}$, and reduced $\mathrm{NO}$ bioactivity. Antihypertensive treatments that reduce Ang II signaling, ameliorate oxidative stress, or increase NO bioavailability have an added benefit of restoring functional sympatholysis. AR, adrenergic receptor; $\mathrm{ARB}$, angiotensin receptor blocker; $\mathrm{AT}_{1} \mathrm{R}$, angiotensin type 1 receptor; $\mathrm{Ang} \mathrm{II}$, angiotensin II; NADPH, nicotinamide adenine dinucleotide phosphate oxidase; NE, norepinephrine; $\mathrm{NO}$, nitric oxide; $\mathrm{O}_{2}^{-}$, superoxide; $\mathrm{PG}$, prostaglandins. 